\title{
Acceptance on Mobile Learning via SMS: A Rasch Model Analysis
}

\author{
doi:10.3991/ijim.v4i2.1144 \\ Issham Ismail, Siti Sarah Mohd Johari and Rozhan Md. Idrus \\ Universiti Sains Malaysia, Penang, Malaysia
}

\begin{abstract}
This study investigated whether mobile learning via Short Message Service (SMS-learning) is accepted by the students enrolled in the distance learning academic programme in the Universiti Sains Malaysia. This study explored the impact of perceived usefulness, perceived ease of use and usability of the system to their acceptability. The survey was constructed using a questionnaire consisting of statements regarding the participants' demographics, experiences in and perception of using mobile learning via SMS, involving 105 students from management and sciences disciplines. The Rasch Model Analysis was used for measurement correspond to a 5 point Likert. Results indicated that the usability of the system contributed to be effectiveness in assisting the students with their study. Respondents agree that SMS-learning is easy, effective and useful to help them study. However, the results found that there has been a problem in mobile learning that less interaction with lecturers. It implies that the acceptability of students to this mode on communication and interaction is highly endorsed.
\end{abstract}

Index Terms-Mobile, Learning, M-Learning, SMS, Rasch Analysis

\section{INTRODUCTION}

When the Universiti Sains Malaysia (USM) was established in 1969, it was conferred the unique distinction of offering courses for part-time students, thus pioneering distance learning in the country in 1971. However, few Malaysians took advantage of this mode of learning [1]. In that time, the delivery mechanism in the teaching and learning process also evolved from the use of the basic self-instructional text to audio and video conferencing to the current use of the electronic portal and numerous web 2.0 tools.

One of the most significant changes in the field of education during the information age is the paradigm shift from teacher-centered to learner-centered education [2]. Education is now being transformed by the use of wireless mobile technologies into m-learning, as organization look for flexible methods, unbounded by space and time, to deliver learning materials to reach learners [3]. It sets in place the first building block for the next generation of learning, which is the movement from distance learning and web-based learning to mobile learning (M-learning) [3]. In many ways, electronic and mobile learning will move closer together as the power and sophistication of mobile learning devices increases, however in particular ubiquity and location awareness, will always be certain aspects of mobility that will make mobile learning a unique and special approach to education [4].
Therefore, a pilot test was conducted in determining the appropriate development design of learning contents, the suitable system to use and the proper hardware to employ. The study expected to develop mobile learning system framework offering merely SMS text messages into the existing learning mechanisms in USM as it may comply with the university effort in supporting the "bottom billion".

It is imperative that we ascertain the learner's acceptance toward SMS-learning in order to inculcate its use in their studies. This was corroborated by Tallent-Runnels et al [7] stated that, in order to have a good m-learning system, there should be an effort to identify accurate evaluation measures that are required to continue doing research. The learners' perceptions in SMS-learning may provide some information related to the factors in the use of SMSlearning. Hence, the primary reason of the study was to understand the acceptance of m-learning via Short Message Service (SMS-learning) and to identify the factors that can predict their intention to accept the systems.

\section{A. Related research}

A study conducted by Ring [5], highlighted the combination of the Web and WAP to deliver e-Learning in order to determine the effectiveness of a course delivered by wireless phone technology. Results indicated that $93 \%$ of students having wireless access reported that the technology made the course more convenient and they could work from anywhere. Students also reported that they were able to access courses while commuting which showed that the wireless technology afforded them freedom to access the course from anywhere and students are able to get an overall feel for the content of the course [5].

The study by Ally and Satuffer [3] attempted to determine how learners perceive the enhancements by using mobile device to distance learning materials or online learning. The results concluded that the majority of students responded that they either agreed or strongly agreed that the use of the mobile device to access the course materials was useful and provided both flexibility and convenience. However, in the study most users would mainly use a desktop for their courses though, with occasional use of the mobile device.

In the research study conducted by Lawrence et al [6], the researchers explored the opinions of the students regarding the use of mobile devices in a university learning environment. Although the respondents identified positive feelings to the use of mobile devices in their university learning, such as the limited use of SMS messages for alerts, the availability of podcasts for lectures, and using the SMS for asking questions anonymously in class, they 
also identified potential problems. The results showed that students were afraid that the use of mobile devices in the learning environment could weaken interpersonal communication and intrude on their privacy. Using SMS was also found to be insufficient for describing complex tasks.

Ismail and M.Idrus took a similar contribution by conducting a research as an attempt to introduce mobile learning as "Convenience Education" which involved the process of determining the design that appropriate for the system, the suitable learning content and also hardware in order to develop a framework that will contribute to the improvement of the education system in Malaysia [19]. Their pilot study was tested on the second year Physics optics course and has received overwhelming agreement and positive responses which may prove that the mobile phone could make a strong and viable contribution to the educational transaction in a Physics course in distance education.

\section{THEORETICAL FOUNDATIONS}

\section{A. Mobile learning}

Theoretically, it is major to understand what is mean by 'mobile learning' as a way of establishing a common understanding as well as a way of exploring the evolution and direction of mobile learning. 'Mobile learning' is definitely not simply the combination of 'mobile' and 'learning' and according to Traxler [22], it has always implicitly meant 'mobile e-learning' and its history and development have to be understood, thus many wider issues should be addressed in terms of explaining, understanding and conceptualizing it [22]. There has never been a specific definition of 'mobile learning' [22] however, there are many evolving definitions that attempt at identifying and defining mobile learning (see Table I).

In the early approaches at defining mobile learning, the focus is more on the mobility of the technology [23] [24] [27] or on the technology alone [26]. Parsons took a similar contribution, saying mobile learning describes any form of education or training that is delivered using some kind of mobile device [4]. In addition, Parsons also highlighted that in many cases these systems take advantage of location awareness and the ability of wireless devices to support communication between groups members, thus mobility enable individuals to participate in distributed simulations and role play across both space and time [4]. Another view of mobile learning says it is the facilitation of learning and the delivery of educational materials to students using mobile devices via wireless medium [6].

Learning with a mobile device will become an integral part of the general spectrum of technology-supported learning complement with its special characteristics including ubiquity, convenience, localization, and personalization, give it unique qualities that help it stands out from other forms of learning [4]. Whilst Winters [28] grants additional perspectives on what might characterize different types of mobile learning dividing it into four broad categories namely technocentric which the mobile learning is viewed as learning using a mobile device, relationship to e-learning which it is viewed as an extension of elearning, augmenting formal education and finally learnercentred.

These are some of the points of discernment at defining and identifying mobile learning and according to Traxler
[22], irrespective of the exact definition, mobile and wireless technologies, including handheld computers, personal digital assistants, camera phones, smartphones, graphing calculators, personal response systems, games consoles and personal media players, are ubiquitous in most parts of the world and have led to the development of 'mobile learning' as a distinctive but still ill-defined entity.

\section{B. Technology Acceptance Model}

Technology Acceptance Model (TAM) was used to address why users accept or reject information technology as it proposes the two main internal beliefs about usefulness and ease of use as the essential elements in determining user's intention towards adopting a new technology. Davis (1989) defined perceived usefulness as "the degree to which a person believes that using a particular system would enhance his or her job performance [8]." This follows from the definition of the word useful specifically "capable of being used advantageously." According to Davis, a system high in perceived usefulness, in turn, is one for which a user believes in the existence of a positive use-performance relationship [8].

TABLE I.

DEFINITION AND TAXONOMY OF 'MOBILE LEARNING'

\begin{tabular}{|c|c|}
\hline Studies & nomy \\
\hline Quinn [23] & $\begin{array}{l}\text { "E-learning through mobile computational devices: } \\
\text { Palms, Windows CE machines, even your digital cell } \\
\text { phone.” }\end{array}$ \\
\hline $\begin{array}{c}\text { O’Malley et al } \\
{[24]}\end{array}$ & $\begin{array}{l}\text { "Any sort of learning that happens when the learner is } \\
\text { not at a fixed, predetermined location, or learning that } \\
\text { happens when the learner takes advantage of learning } \\
\text { opportunities offered by mobile technologies" }\end{array}$ \\
\hline $\begin{array}{l}\text { Naismith et al } \\
{[25]}\end{array}$ & $\begin{array}{l}\text { Suggest that mobile technologies can relate to six types } \\
\text { of learning, or 'categories of activity', namely behav- } \\
\text { iourist, constructivist, situated, collaborative, infor- } \\
\text { mal/lifelong, and support/coordination. }\end{array}$ \\
\hline Traxler [26] & $\begin{array}{l}\text { "any educational provision where the sole or dominant } \\
\text { technologies are handheld or palmtop devices" }\end{array}$ \\
\hline Keegan [27] & $\begin{array}{l}\text { 'The provision of education and training on } \\
\text { PDAs/palmtops/handhelds, smartphones and mobile } \\
\text { phones.' }\end{array}$ \\
\hline Winter & $\begin{array}{l}\text { “Current perspectives on mobile learning generally fall } \\
\text { into the following four broad categories: } \\
\text { - Technocentric. This perspective dominates the } \\
\text { - } \quad \text { literature. } \\
\text { Relationship to e-learning. This perspective char- } \\
\text { acterizes mobile learning as an extension of e- } \\
\text { learning. } \\
\text { - } \quad \text { Augmenting formal education. } \\
\text { - Learner-centred.” }\end{array}$ \\
\hline Jones et al [29] & 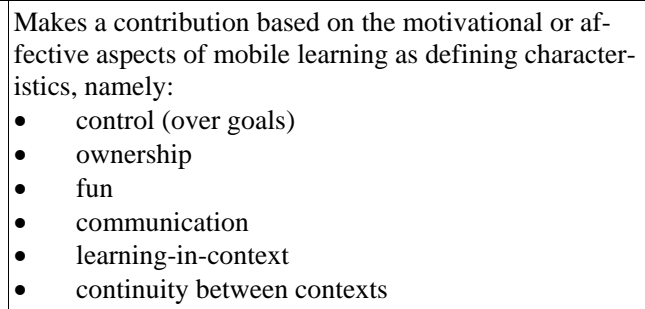 \\
\hline Traxler [22] & $\begin{array}{l}\text { Take learning to individuals, communities and countries } \\
\text { that were previously too remote, socially or geographi- } \\
\text { cally, for other types of educational initiative. }\end{array}$ \\
\hline $\begin{array}{l}\text { MoLeNET } \\
{[31]}\end{array}$ & $\begin{array}{l}\text { "exploitation of ubiquitous handheld hardware, wireless } \\
\text { networking and mobile telephony to enhance and ex- } \\
\text { tend the reach of teaching and learning" }\end{array}$ \\
\hline
\end{tabular}


Whilst perceived ease of use, in contrast, refers to "the degree to which a person believes that using a particular system would be free of effort [8]." This follows from the definition of ease: "freedom from difficulty or great effort." All else being equal, Davis claimed, an application perceived to be easier to use than another is more likely to be accepted by users [8].

Usability is typically described in terms of five characteristics: ease of learning, efficiency of use, memorability, error frequency and severity, and subjective satisfaction [9]. Bevan defined usability as the extent to which a product can be used by specified users to achieve specified goals with effectiveness, efficiency and satisfaction in a specified context of use [10]. Considerations of usability principles for mobile Internet applications suggest that mobile learning solutions warrant a specific approach, Uther suggested it may suited to particular aspects of elearning courses, such as: quick reminders and alerts; daily tips; glossary information; searching for specific information within a topic and course registration [11]. Thus, this variable was believed to have a significant effect to mobile learner's acceptance.

Technology acceptance, in general, has been widely studied and several models of technology acceptance has been proposed and tested [8] [32]. According to Van Biljon and Kotzé, technology adoption models specify a pathway of technology acceptance from external variables to beliefs, intentions, adoption and actual usage [32]. They had studied mobile phone adoption from a variety of perspectives, including sociology, computer-supported cooperative work and human-computer interaction since there is lacking of model integrating all these factors influencing mobile phone adoption. They had proposed a MOPTAM model representing factors that influence mobile phone adoption and it differs from TAM in the refinement of the external variables, the inclusion of social influence and the adaptation to the mobile context, which includes the addition of facilitating conditions [32].

This study intends to identify the acceptance of extending the learning merely through SMS amongst distance learners in USM and for that reason; this study proposes perceived usefulness, perceived ease of use and usability which may contribute to the students' acceptance of the SMS-learning project.

\section{METHOD}

\section{A. Participants}

The respondents are distance education learners from School of Distance Education (SDE), Universiti Sains Malaysia (USM), consisting of 105 students with a gender distribution of 31 males and 74 females ranging in age from 20 to above-50. Responses included $43.8 \%$ second year students, 53.3\% third year students and 2.9\% are fourth year students. The participants were selected from Management programme, Sciences, Arts and Social Sciences. The ethnic make-up consisted of Malays (57.1\%), Chinese (25.7\%) and Indian (10.5\%) and 6.7\% claimed they were indigenous. All of them affirmed that they have or owned mobile phones.

\section{B. SMS M-Learning}

Previously, none of the participants has had any experience in this kind of project and they volunteered to par- ticipate in the SMS-learning project which was conducted in the second semester of the 2008/2009 academic session. The subjects that were delivered in this study are Financial Principle for second year Management and International Business for third year Management. Besides, there are subjects also delivered to Physics students namely Mechanics and Optics for second year. For Economic students, the subjects that were delivered are Money \& Banking for the second year and Quantitative Economy for the third year.

The participants involved in this project had volunteered and agreed to use their own mobile phones and all the expenses of SMS communication were liable on the university research grant. In other words, students received the SMS for free.

This program was conducted for 3 months from February 2009 to April 2009, encompassing the related subject matter in the semester via text message received once a day.

\section{Instruments}

The survey was conducted based on quantitative research design which is constructed using a questionnaire consisting of statements regarding the participants' demographics, experiences in and perception of using mobile learning via SMS. Questionnaire items appropriate for Rasch analysis included 23 statements that pertain to technology acceptance which stress on perceived ease of use, perceive usefulness and usability. Responses to the items correspond to a 5 point Likert scale, where $1=$ strongly disagree, 2 = disagree, $3=$ neutral, $4=$ agree and 5 = strongly agree.

The questionnaires were sent through email to 170 distance learners involved in the project. The distribution of questionnaires was performed immediately after dissemination of the learning contents through SMS had finished at the end of April 2009. The collection of questionnaires from respondents was conducted one month after the distribution. At the end of the survey, 105 questionnaires were returned.

\section{Rasch Unidimensional Measurement Model (RUMM)}

Data from the survey was entered into the Rasch model computer program Rasch Unidimensional Measurement Model (RUMM) [31] and this project utilized Winsteps 3.68.2 software. According to the study by Cavanagh and Romanoski which also was using Rasch analysis, RUMM calibrates the score of a respondent against the difficulty respondents demonstrated in verifying particular items by application of the Rasch rating scale model [20]. The model applies a logistic equation in which the probability of choosing a particular category in the scale is an exponential function of the difference between the repondents' ability to agree (agreeableness') and the item's difficulty in permitting agreeable responses ('disagreeableness') [20].

RUMM summary test-of-fit statistics were estimated to test the global fit of data from the 23 items to the Rasch measurement model. The psychometric properties of data from each of the 23 items were also examined by calculating individual item fit statistics. Concurrently, the capacity of the items to elicit logical and consistent responses to the five response categories was examined by calculating the 
thresholds between the five response categories for each item. A threshold is the minimum level of 'agreeableness' which a student must have in order to go from one Likert scale response category to the next [20]. As mentioned by Cavanagh and Romanoski, when respondents are logical in their choice of response categories, the thresholds should ideally follow in a sequence from lowest to highest; in keeping with the order of the response categories from strongly disagree to strongly agree [20].

Then, the results of the RUMM analysis were scrutinised to see if the measurement capacity of the instrument could be improved by deleting certain items. Consequently, items obtaining data with poor fit to the model were deleted from a subsequent RUMM analysis of data from a modified instrument on the assumption that this version of the instrument would be a more accurate measure.

\section{E. Data Analysis}

A stepwise refinement process was undertaken to remove items from the scale that were contributing to large errors of measurement to produce a refined scale that was a more accurate measure whereby at the end, out of 23item data, 17 items were retained . Therefore, the RUMM verified the fit of the data to the model is acceptable.

In order to justify whether students are actually accepting this new education technology of using SMS-learning or not, the perceived ease of use, perceived usefulness and usability of the system are highlighted. Rasch is mathematically identical to the most Item Response Theory (IRT) model; however, it is a comparatively more viable proposition for practical testing since it can be applied in the context in which persons interacts with items [12]. Data were analyzed using Winsteps software version 3.68.2. Code was written to represent each respondent and Likert-type survey treatment. The Rasch model permits item difficulty for each statement presented in the survey derived by the way suitable participants actually respond to the statements [13].

Throughout the analysis, table and figure are used to describe and analyze the perceived ease of use, perceived usefulness and usability as well as its components. A statistical summary table is produced to describe the separation rate and reliability of the students and the items. Separation is the number of statistically different performance strata that the test can identify in the sample while the reliability rate indicates whether the test discriminates the sample into enough levels for the intended measure [12]. Infit and outfit statistics and variable maps provided the basis for determining how well the items measured each item. The statistics show how well the data fit the model, with fit implying a meeting of requirements or matching of intentions [12]. Variable map or also known as item/person map was constructed to illustrate the empirical hierarchy of the items on the survey, because it was connected to the participant's level of ability to endorse each item [14].The items listed at the lower end of the map represent a higher probability of being endorsed, at the same time opposed to those at the top which represent a lower probability of being endorsed. A similar pattern applied to participants. For example, for those at the lower end of the map represent less willingness to favorably endorse an item. The variable map visually reveals the hierarchy and the order of the items as well as any potential gaps in the measure [12].

\section{RESULTS AND DisCUSSION}

Responses from distance education students across the nation were included in this analysis. In order to have an overall view of the reliability and validity of the instrument and the associated responses, the statistical summary tables of the students and the items were produced. The person reliability in this study was 0.94 , with a separation of 3.95 while item reliability gained 0.71 , with a separation of 1.55 . Given a 0.7 threshold of acceptability, both scales for person and item are deemed reliable and usable for the purpose of this study. More so, the survey comes out with 0.97 Cronbach alphas indicated that there was consistency reliability in the instruments. Thus, the survey as a whole appears to have functional reliability.

\section{A. Fit statistics}

Prior to interpreting item maps, fit statistics were examined to determine whether the statements/items "fit" the construct. When applying the Rasch model, data must fit the model, with the assumption of a uni-dimensional domain being measured [12]. Each statement should play a significant part in the way a construct is being investigated.

Table II portrays fit-order statistics presenting items that appear to be influenced by outside factors (outfit) and those that display "off-variable noise" (infit). Rasch measurement summary test-of-fit statistics were estimated for 23-item data. In regard to the issue of uni-dimensionality, Smith [15] suggested that items that produce standardized scores that differ by more than \pm 2.0 from the actual score are items that are only weakly related to the rest of the items comprising the scale. When addressing infit and outfit, a mean squared value range cutoff is determined by the size of the sample. Specifically, the items of this study was agreed to fall within the acceptable infit and outfit limits of 0.6 to 1.5 ([16] [17] [13]) which is less than 2. At the end, out of 23 items, 17 items were retained.

TABLE II.

ACCEPTABLE FIT STATISTICS FOR SMS-LEARNING ACCEPTANCE

\begin{tabular}{|c|c|c|c|}
\hline Item & Statement & $\begin{array}{c}\text { Infit } \\
\text { MNSQ }\end{array}$ & $\begin{array}{l}\text { Outfit } \\
\text { MNSQ }\end{array}$ \\
\hline USA17 & $\begin{array}{l}\text { You think SMS-learning is effective to } \\
\text { help your study. }\end{array}$ & .97 & .98 \\
\hline USA15 & $\begin{array}{l}\text { It is safe to use the system to save your } \\
\text { learning materials. }\end{array}$ & 1.27 & 1.15 \\
\hline PU12 & $\begin{array}{l}\text { Overall, mobile learning is useful to assist } \\
\text { my learning. }\end{array}$ & .86 & .84 \\
\hline PEU4 & $\begin{array}{l}\text { Learning to get use with mobile learning is } \\
\text { easy for me. }\end{array}$ & .90 & .84 \\
\hline USA16 & The system is effective and efficient & 1.03 & .98 \\
\hline PU8 & $\begin{array}{l}\text { Using mobile learning makes it easier } \\
\text { form to facilitate my study. }\end{array}$ & .85 & .87 \\
\hline PU11 & $\begin{array}{l}\text { Using mobile learning improves my per- } \\
\text { formance of undertaking my study. }\end{array}$ & .95 & .92 \\
\hline PU9 & $\begin{array}{l}\text { Using mobile learning enables me to focus } \\
\text { on my study more quickly. }\end{array}$ & .91 & .95 \\
\hline PU7 & $\begin{array}{l}\text { Using mobile learning enhances my effec- } \\
\text { tiveness of utilizing learning and educa- } \\
\text { tion. }\end{array}$ & .96 & .96 \\
\hline PEU5 & $\begin{array}{l}\text { It is easy for me to become skillful by } \\
\text { using mobile devices in my study. }\end{array}$ & 1.06 & 1.03 \\
\hline PEU1 & $\begin{array}{l}\text { I find it easy to learn what I want to learn } \\
\text { in mobile learning. }\end{array}$ & .85 & 1.15 \\
\hline
\end{tabular}




\begin{tabular}{|c|c|c|c|}
\hline Item & Statement & $\begin{array}{c}\text { Infit } \\
\text { MNSQ }\end{array}$ & $\begin{array}{r}\text { Outfit } \\
\text { MNSQ }\end{array}$ \\
\hline PEU6 & I find mobile learning to be flexible. & .83 & .75 \\
\hline PEU2 & $\begin{array}{l}\text { Overall, I find it is easy for me to use } \\
\text { mobile device in my study. }\end{array}$ & .82 & .77 \\
\hline USA13 & The system is easy to use. & 1.02 & 1.00 \\
\hline PU10 & $\begin{array}{l}\text { Using mobile learning for my study in- } \\
\text { creases my productivity in my job. }\end{array}$ & .94 & 1.02 \\
\hline USA14 & It is easy to learn by using the system. & .94 & .91 \\
\hline PEU3 & $\begin{array}{l}\text { My interaction with lecturer via mobile } \\
\text { learning is clear and understandable. }\end{array}$ & 1.31 & 1.35 \\
\hline
\end{tabular}

\section{B. Variable map}

The variable map is another visual guide to information regarding relative scales. There are gaps presenting in the map, which could call for better scale coverage. In the context of evaluation, it could also indicate that goals are being met or exceeded [12]. A good Likert-type instrument is grounded in items with a varying degree of difficulty to assess a range of attitude held by participants [18] Moreover, there is a general spread of the items.

Figure 1 presents a map of the items, ranked by level of difficulty to endorse, from the least favorite item (hardest to endorse) to the most favorite item (easiest to endorse). Respondents ranked by their willingness to endorse the items from students who are accepted with the project to those who are least accepted with the project. Within the map, items have been labeled by a key word in the statement. Items that are located at the top of the map have been identified as those that are more difficult to endorse [18]. Furthermore, those at the bottom are easier to endorse. This concludes that, from bottom to the top of the map, items are more difficult to endorse.

Results suggest the easiest item to endorse is item USA17, You think SMS-learning is effective to help your study. This indicates the respondents' most preferable quality of SMS-learning is the usability of the technology whereby they claimed this project to be effective to assist their study. It illustrates that the students highly accepted the project provided it is usable to help them in their study even though it may has relative weaknesses. Besides, they feel it is safe to save the learning materials by using the system (USA15). It appears that students feel positive about each item, since the mean of students' acceptance is almost two standard deviations higher than the mean of item. It is reasonable to conclude that students value the outcome more than the process. Moreover, this result is inline and consistent with item PU12, where they claimed "mobile learning is useful for me to assist my learning". These outcomes actually showed that students are in need of assistance in their study, and SMS-learning is effective and useful to help them study. Moreover, the interesting part shown in the result is item PEU4 whereby the students felt easy to get use with mobile learning. The possible reason behind this result is that the learning does not require a lot of mental effort as the content was customized for the learners' needs. The results are consistent with Ring [5] which showed that students were able to get an overall feel for the content of the course.

The analysis showed item PEU3 is the most difficult items to endorse, my interaction with lecturer via mobile learning is clear and understandable, as well as item
USA14, It is easy to learn by using the system. It is possible that students negatively perceive ease of use when they begin to experience the project since it is very new and judgeless. This project of SMS-learning is still in the early stage of development, therefore the interaction between students and lectures are limited by the system. The interaction needed in the learning and teaching process is restricted by the inadequacy of the system which only allows the students to receive the messages. Besides, students might feel quite uneasy to learn by using short and briefed SMS since for years they are "customized" to learn by using thick text books and notes. These results are inline with Lawrence et al [6] since using SMS according to them is insufficient for describing complex tasks.

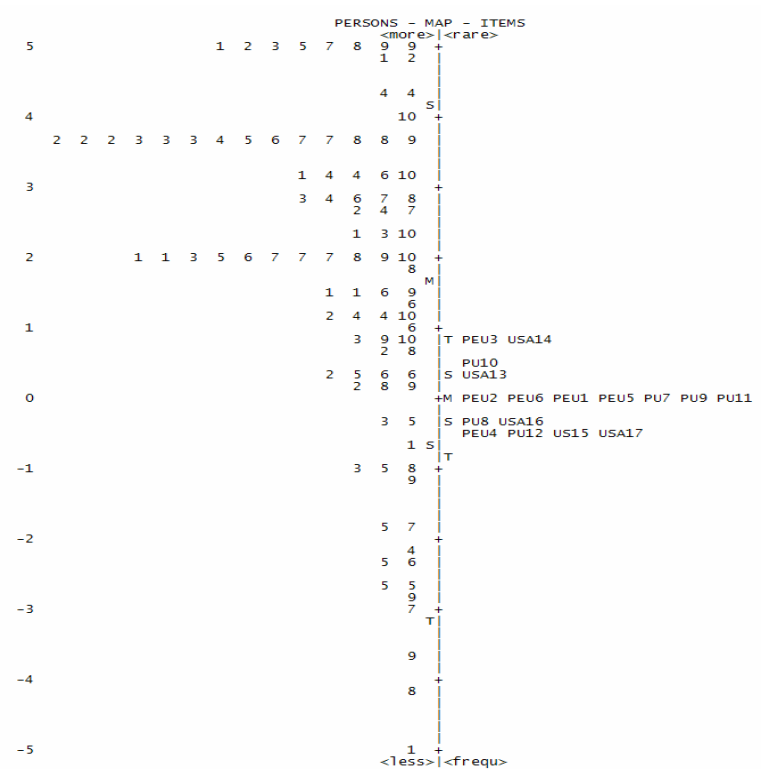

Figure 1. Variable map of students' acceptance of SMS-learning

\section{CONCLUSION}

This study developed and tested a mobile adoption model of learning through SMS and it was found that the majority of the students accepted the usability of this SMS-learning programme and perceived the whole project as useful. It illustrates that the students highly accepted the SMS-learning is safe, easy, effective and usable to help them in their study even though it may has relative weaknesses. Through the results of the Rasch model for measurement, the students' willingness to endorse items and the corresponding items are clearly stated and compared along one scale as they were analyzed and evaluated. The survey instrument is reliable and was able to separate both the sample of students and items.

This study provided evaluation and improvement suggestions to the use of the SMS in distance education. Unbounded by time and space, the SMS-learning has the potential to embed itself as the new medium of teaching and assisted learning. Moreover, to test the rationale and reasoning for response patterns presented, additional data should be collected utilizing students with various ability and interest. Even so, this calibration frame has allowed for a preliminary evaluation of survey instruments, providing a foundation for future applications. Thus, this study suggested there was no problem to imply SMSlearning as an extension to the existing learning mecha- 
nisms provided the system must be usable and useful in order to offer acceptance from its users.

\section{ACKNOWLEDGMENT}

The authors would like to thank Universiti Sains Malaysia for the support under RU grant and USM Fellowship scheme.

\section{REFERENCES}

[1] Raghavan,S \& Kumar, P.R. (2007). The Need for Participation in Open and Distance Education: The Open University Malaysia Experience. Turkish Online Journal of Distance Education-TOJDE, 8(4), 102-113

[2] Lee, B-C., Yoon, J-O., Lee, I. (2009). Learners' acceptance of the e-learning in South Korea: Theories and results. Computers \& Education, In Press, Corrected Proof (doi:10.1016/ j.compedu.2009.06.014)

[3] Mohamed Ally \& Satuffer, K. (2008). Enhancing Mobile Learning Delivery through Exploration of the Learner Experience. Proceedings of the Fifth IEEE International Conference on Wireless, Mobile, and Ubiquitous Technology in Education, 23 March - 26 March, 2008, Beijing, China, pp.128-132

[4] Parsons, D. (2007). Mobile Learning, in D. Taniar (Ed.) Encyclopedia of Mobile Computing and Commerce, IGI Global, 525-527

[5] Ring, G. (2001). Case study: Combining Web and WAP to deliver e-Learning. Learning Circuits, ASTD Online Magazine, http://www.learningcircuits.org/2001/jun2001/ring.html

[6] Lawrence, E., Bachfischer , A., Dyson, L.E., Litchfield , A.(2008).Mobile Learning and Student Perspectives: An mReality Check! $7^{\text {th }}$ International Conference on Mobile Business, 7 July - 8 July 2008, Barcelona, pp. 287-295

[7] Tallent-Runnels, M.K., Thomas, J.A., Lan, W.Y., Cooper, S., Ahem, T.C., Shaw, S.M., \& Liu,X. (2006). "Teaching Courses Online: A Review of the Career Decision-making Self-efficacy, Career Salience, Locus of Control and Vocational Indecion”. Journal of Vocational Behavior, 37(1), 17-31

[8] David, F.D. (1989). Perceived Usefulness, perceived ease of use, and user acceptance of information technology. MIS Quarterly, 13(3), 319-340. (doi:10.2307/249008)

[9] Nielsen, J. (1993). Usability Engineering, Boston: Academic Press.

[10] Bevan, N. (1997). Quality and usability: A new framework. In: van Veenendaal, E, and McMullan, J (eds) Achieving software product quality (pp.1-8), Tutein Nolthenius, Netherlands.

[11] Uther, M. (2002). Mobile Internet usability: What can 'Mobile Learning' learn from the past? IEEE International Workshop on Wireless and Mobile Technologies in Education (WMTE'02), 29August - 30 August, 2002, Växjö, Sweden, pp.174Y. Yorozu, M. Hirano, K. Oka, and Y. Tagawa, "Electron spectroscopy studies on magneto-optical media and plastic substrate interface," IEEE Transl. J. Magn. Japan, vol. 2, pp. 740-741, August 1987 [Digests $9^{\text {th }}$ Annual Conf. Magnetics Japan, p. 301, 1982].

[12] Ren, W., Bradley, K.D., and Lumpp J.K. (2008). Applying the Rasch Model to Evaluate an Implementation of the Kentucky Electronics Education Project. Journal of Science Education and Technology, 17(6), 618-625 (doi:10.1007/s10956-008-9132-4)

[13] Bond, T.G \& Fox, C.M (2001). Applying Rasch model: Fundamental measurement in the human sciences. Mahwah, NJ: Lawrence Erlbaum Associates

[14] Bradley, K. D., Cunningham, J. D., Haines, R. T., Harris, Jr. W. E., Mueller, C. E., Royal, K. D., Sampson, S. O., Singletary, G. \& Weber, J. (2006). Constructing and evaluating measures: Applications of the Rasch measurement model. Symposium presented at the Mid-Western Educational Research Association Annual Meeting, Columbus, OH, pp.1-54

[15] Smith, R.M. (1996). A comparison of methods for determining dimensionality in Rasch measurement, Structural Equation Modeling, 3(1), 25-40. (doi:10.1080/10705519609540027)
[16] Fox, C. (1999). An introduction to the partial credit model for developing nursing assessments. Journal of Nursing Education, 38(8), 340-346.

[17] Singletary, G. (2006). An exploratory examination of traditional religious principles and objectivity. Constructing and evaluating measures: Applications of the Rasch measurement model. Symposium presented at the Mid-Western Educational Research Association Annual Meeting, Columbus, OH, pp.9-13

[18] Harris, Jr. (2006). A study of Black University Students' Perceptions of Marriage. Constructing and evaluating measures: Applications of the Rasch measurement model. Symposium presented at the Mid-Western Educational Research Association annual meeting, Columbus, OH, pp.19-24

[19] Ismail, I. B., \& M.Idrus, R. (2009). Development of SMS Mobile Technology for M-Learning for Distance Learners. International Journal of Interactive Mobile Technologies (iJIM), 3(2), 55-57. doi: 10.3991/ijim.v3i2.724.

[20] Cavanagh, R.F.\& Romanoski , J.T. (2005). Parent views of involvement in their child's education: A Rasch model analysis. $\mathrm{Pa}$ per presented at the 2005 annual conference of the Australian Association for Research in Education, 27 November - 1 December, 2005, University of Western Sydney, and Parramatta, pp.1-15

[21] Ju, T.L., Sriprapaipong , W., Minh , D.N. (2007). On the Success Factors of Mobile Learning. $5^{\text {th }}$ International Conference on ICT \& Higher Education, Knowledge Management, 21 November - 23 November, 2007, Siam University, Bangkok, Thailand, pp.1-12

[22] Traxler, J. (2009). Learning in a Mobile Age. International Journal of Mobile and Blended Learning, 1(March), 1-12. Retrieved from http://wlv.academia.edu/documents/0009/9949/ijmblproof01.pdf.

[23] Quinn, C. (2000) mLearning: Mobile, Wireless, in your Pocket Learning. LineZine, Fall 2000. http:// www.linezine.com/2.1/features/cqmmwiyp.htm.

[24] O’Malley, C., Vavoula, G., Glew, J., Taylor, J., Sharples, M. \& Lefrere, P. (2003). Guidelines for learning/teaching/tutoring in a mobile environ- ment. Mobilearn project deliverable. Available from http://www.mobilearn.org/download/results/ guidelines.pdf

[25] Naismith, L., Lonsdale, P., Vavoula, G. \& Sharples, M., (2004), Literature Review in Mobile Technologies and Learning. Bristol: NESTA FutureLab

[26] Traxler, J. (2005). Mobile learning- it's here but what is it? Interactions 9, 1. Warwick: University of Warwick

[27] Keegan, D. (2005) The Incorporation of Mobile Learning into Mainstream Education and Training. Proceedings of mLearn20054th World Conference on mLearning, Cape Town, South Africa, 25-28 October 2005. http://www.mlearn.org.za/CD/papers/keegan1.pdf

[28] Winters, N. (2006). What is mobile learning? .In M. Sharples (Ed), Big Issues in Mobile Learning (pp. 1-34). Kaleidoscope Network of Excellence, Mobile Learning Initiative. Retrieved from http://telearn.noe-kaleidoscope.org/warehouse/Sharples2006.pdf.

[29] Jones, A., Issroff., K., Scanlon, E., Clough, G., \& Mcandrew, P. (2006). Using mobile devices for learning in Informal Settings: Is it. Motivating? Proceedings of IADIS International conference Mobile Learning. July, 14, -16.

[30] Mobile Learning Network (MoLeNET ). (2009). What is mobile learning? Retrieved December 30, 2009, from http://www.molenet.org.uk/

[31] Andrich, D., Sheridan, B., Lyne, A. \& Luo, G. (2000). RUMM: A windows-based item analysis program employing Rasch unidimensional measurement models. Perth: Murdoch University.

[32] Van Biljon, J., \& Kotzé, P. (2007). Modelling the factors that influence mobile phone adoption. In Proceedings of the 2007 annual research conference of the South African institute of computer scientists and information technologists on IT research in developing countries (p. 161). New York, New York, USA: ACM. doi: $10.1145 / 1292491.1292509$. 


\section{AUTHORS}

Issham Ismail is with the School of Distance Education, Universiti Sains Malaysia, Minden, Pulau Pinang, 11800 Malaysia (e-mail: issham@ usm.my).

Rozhan M. Idrus, is with the School of Distance Education, Universiti Sains Malaysia, Minden, Pulau Pinang, 11800 Malaysia. He is specialized in Open and Distance Learning Interactive Technologies and e-Learning (e-mail: rozhan@usm.my)
Siti Sarah Mohd Johari is a student under the School of Distance Education, Universiti Sains Malaysia, Minden, Pulau Pinang, 11800 Malaysia, and currently furthering her study in Masters of Education Technology (email: sitisarahmjohari@gmail.com).

This work was supported in part by the Universiti Sains Malaysia under RU Grant 1001/PJJAUH/817015

Submitted November 17th, 2009. Published as resubmitted by the authors March 18th, 2010. 